\title{
FRICTION STIR PROCESSING OF COPPER
}

\author{
Józef IWASZKO, Krzysztof KUDŁA
}

Czestochowa University of Technology, Czestochowa, Poland, EU, iwaszko@wip.pcz.pl, kkudla@gmail.com

https://doi.org/10.37904/metal.2019.874

\begin{abstract}
The main purpose of the work was to modify the surface layer of copper using FSP technology (Friction Stir Processing). The surface treatment was performed using a tool equipped with a threaded pin. Changes in the microstructure of the material were evaluated by light microscopy and scanning electron microscopy. Comparative measurement of the hardness of the starting and treated material was also carried out. It was found that the friction modification leads to strong refinement of the copper microstructure and the formation of zones with different sizes and morphology of the grains. In the stirring zone, the presence of very fine, mostly equiaxed grains, measuring from $3 \mu \mathrm{m}$ to $32 \mu \mathrm{m}$, depending on the location in the zone, were revealed. In the narrow thermomechanically affected zone that intermeshed with the heat affected zone, non-equiaxed grains of an elongated shape prevailed. The observed changes in the copper microstructure were accompanied by a significant increase in hardness, the value of which corresponded to the degree of microstructure fragmentation. The results of the research prove that using FSP technology to modify the surface layer of copper is an effective and promising solution with a high application potential, allowing controlled shaping of the material microstructure and an alternative solution to other methods and technologies used in surface engineering.
\end{abstract}

Keywords: Friction stir processing, copper, microstructure

\section{INTRODUCTION}

Friction Stir Processing (FSP) is a new and promising method, dynamically gaining importance in modern surface engineering and becoming a competitive solution to other methods and techniques of shaping the surface layers of engineering materials [1,2]. In contrast to FSW (Friction Stir Welding) [3], the FSP method is not used to join materials, but to shape the microstructure and properties of the surface layer. The heat source necessary for plasticizing the material in both the FSW and FSP methods is the friction of a special tool against the surface of the material. The amount of heat generated during FSP is primarily determined by the rotational speed and pressure of the tool, the shape and dimensions of the pin and the diameter of the shoulder. It is worth mentioning here that 80 to $90 \%$ of the heat generated during FSP is created as a result of friction of the tool shoulder [4]. The shape of the pin influences the efficiency of mixing the plasticized material. Depending on the type of modified material and the expected treatment results, pins with different profiles are used: square, conical threaded, triangular, cylindrical and others. In the case of tools based on regular polygons, the intensity of radial mixing depends on the number of side walls of the pin [5]. During treatment, the tool generates not only a thermal effect, but also causes strong plastic deformation of the material. As a consequence of the combined effect of heat and force on the material, the material recrystallizes dynamically. During FSP treatment, the melting temperature of the modified material is not exceeded, therefore the material microstructure is formed only by solid state transformations. In the surface layer of the modified material, a number of zones differentiated in terms of microstructure are formed, reflecting the conditions in which the material is shaped. During FSP, it is possible to introduce additional material to the plasticized matrix and thus create a composite microstructure [6-8]. All this makes FSP technology an extremely attractive solution with a high application potential. A number of engineering materials, e.g. magnesium alloys [1], aluminum alloys [8,9], steels [10], and even plasma sprayed coatings [11] are subjected to attempts to modify their microstructure 
using FSP technology. Copper has also recently been the subject of research [6,7,12-15]. In the case of copper, the main purpose of FSP treatment is primarily to improve its mechanical properties. Copper in its pure form has poor strength, wear and fatigue resistance and hence is unsuitable for high end applications like contact terminals of electrical switches and sliding surfaces [14]. Frictional modification of copper has been carried out, among others, by Salahi and Rezazadeh [12]. They processed samples of pure copper to a depth of $4 \mathrm{~mm}$ under different process conditions by varying the traverse speed from $40 \mathrm{~mm} \cdot \mathrm{min}^{-1}$ to $100 \mathrm{~mm} \cdot \mathrm{min}^{-1}$ at rotation speeds of $300 \mathrm{rpm}$ and $600 \mathrm{rpm}$. The authors showed that the grain size in the FSP modified zone is controlled by the heat input, while cavity formation in the samples decreases with higher plastic deformation produced by the tool. The authors also stated that at the tool rotation speed of $300 \mathrm{rpm}$ the insufficient heat input and low plastic deformation generates cavities and cracks and leads to low ductility in the FS processed samples. The problem was eliminated by using a higher tool rotation speed i.e. $600 \mathrm{rpm}$. In turn, in work [15] Cartigueyen et al. investigated the heat generation during the friction stir processing of copper. In the analyzed samples, the authors found very strong microstructure refinement of the material in the stirring zone, but the finest grains were observed on the retreating side of the SZ near the tool pin. The authors also demonstrated that the heat generated during FSP strongly depends on both the rotational and transverse speed and that the peak temperature is affected by the rotational speed while the heating rate has an influence on the transverse speed. The issue of copper processing using FSP technology has high application and cognitive potentials, but it requires further systematic research so that the possibilities offered by the FSP method can be effectively used in the process of controlled shaping of the microstructure and properties of a given material.

\section{RESEARCH MATERIAL AND PROCESSING METHODOLOGY}

From commercially available pure copper flat bars samples having the dimensions $100 \mathrm{~mm}$ long, $80 \mathrm{~mm}$ wide and $10 \mathrm{~mm}$ thick were cut. FSP was carried out in a CNC vertical milling machine. The FSP station is shown in Figure 1. The friction treatment was performed using a tool equipped with a $4.5 \mathrm{~mm}$ long pin. The pin had the shape of a truncated cone with a threaded side surface. The tool was made of X37CrMoV5-1 hot work tool steel. The tool speed "V" was constant and was $60 \mathrm{~mm} \cdot \mathrm{min}^{-1}$ while "l" - the speed of plunging the tool into the modified material was equal to $6 \mathrm{~mm} \cdot \mathrm{min}^{-1}$. The rotational speed of the tool "N" varied in the range of 600 $1,000 \mathrm{rpm}$. The tool tilt angle was $1^{\circ}$. Single stir passes were used. The test material was subjected to macroscopic examination using an Olympus SZ61 stereoscopic microscope and microscopic examination using an Olympus GX41 light microscope as well as a Jeol JSM-6610LV scanning electron microscope. Moreover, a comparative measurement of the starting material and friction-modified material hardness was carried out. Hardness measurements were conducted on cross-sections of the friction stir processed zone using a Shimadzu HMV-G20 microhardness gauge with loads of $980.7 \mathrm{mN}$ applied for $10 \mathrm{~s}$.

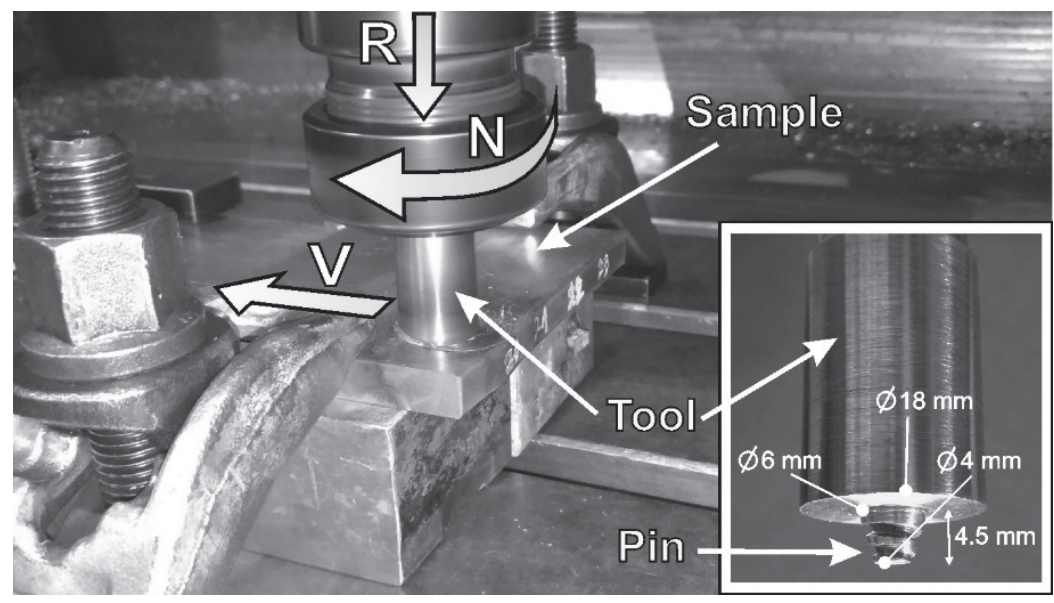

Figure 1 FSP station for copper modification 


\section{RESULTS}

\subsection{Macroscopic examination}

The macroscopic effect of the FSP of pure copper and changes in the geometric structure of the surface, characteristic for this technology, are shown in Figure 2a and Figure 2b. Characteristic parallel grooves which indicate the direction and way of movement of the plasticized material movement under the tool shoulder were the main macroscopic effects observed on the surface (Figure 2b). The width of the bands was about $18 \mathrm{~mm}$ and corresponded to the diameter of the shoulder. In the case of the sample treated with the lowest tool rotational speed, i.e. $600 \mathrm{rpm}$, tool dragging was found at a length of about $40 \mathrm{~mm}$ from the place of pin penetration. The presence of tool dragging proves the too low plastic deformation of the copper and a too small amount of plasticized copper for the modified material to fill the space behind the moving pin. It may also be a result of the too short friction time of the tool in the initial phase, resulting in insufficient heat generation. In this case, it is also necessary to take into account the properties of copper, i.e. very high thermal conductivity, as a result of which the outflow of heat from the processing area occurs very dynamically and the copper quickly loses the plasticizing effect. In the case of the sample treated with $\mathrm{N}=800 \mathrm{rpm}$, there was limited range of tool dragging, and at $N=1,000 \mathrm{rpm}$ this effect was completely eliminated. Therefore, the sample treated at $\mathrm{N}=1,000 \mathrm{rpm}$ was subjected to microstructural investigations .

a)
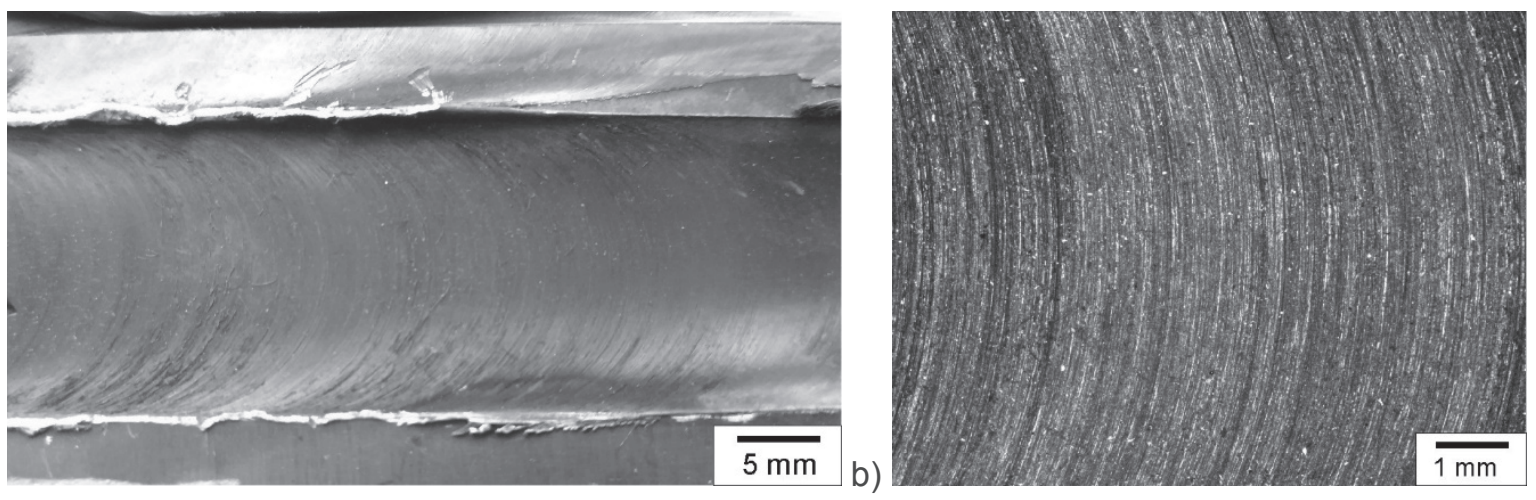

Figure 2 Macroscopic effect of treatment (a), characteristic grooves on strip surface (b). $N=1,000 \mathrm{rpm}$

\subsection{Microstructure}

The microstructure of the material in the initial state is shown in Figure 3. The average grain size was about $60 \mu \mathrm{m}$. In the examined material, no microstructural defects such as pores or micro-cracks were found. The material was solid and homogeneous.

a)

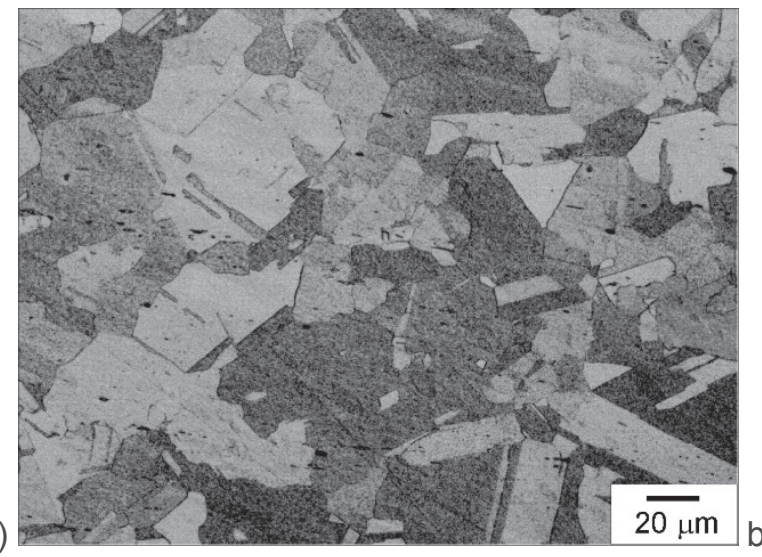

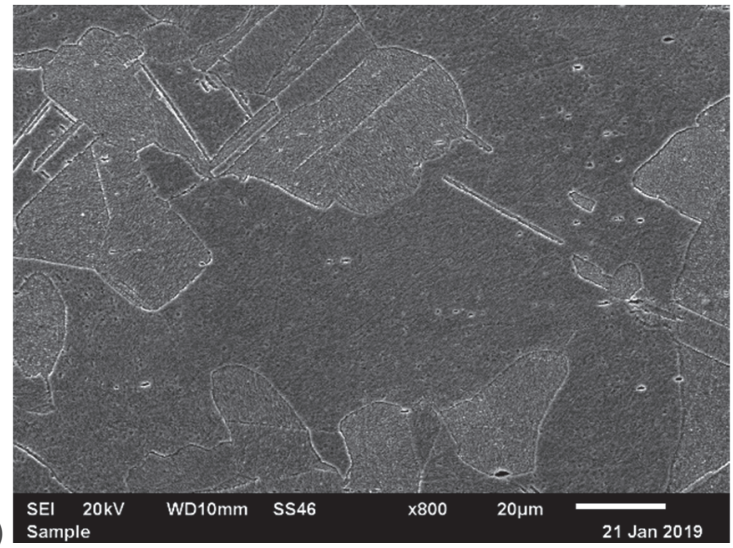

sis

Figure 3 Microstructure of material in initial state. Light microscopy (a), SEM (b) 
A different microstructure was found in the material subjected to friction treatment. In this material, strong grain refinement was found as well as the presence of characteristic zones, i.e. the stirring zone (SZ) and the narrow thermomechanically deformed zone (TMAZ) meshing with the heat affected zone (HAZ) and the base material (BM). The boundary between HAZ and TMAZ was not clearly visible. In the stirring zone very fine equiaxed grains dominated, the size of which varied depending on the distance from the surface. In the very narrow subsurface zone, the thickness of which oscillated around 70-80 $\mu \mathrm{m}$, the presence of very fine grains with an average size of less than $5 \mu \mathrm{m}$ was found. This zone is marked in Figure $\mathbf{4 a}$. In the next zone, following the subsurface zone, there were grains with clearly larger sizes, ranging from $10 \mu \mathrm{m}$ to $32 \mu \mathrm{m}$, with an average grain size in this zone of approximately $18 \mu \mathrm{m}$. In the central part of the stirring zone grains of $8 \mu \mathrm{m}$ to $16 \mu \mathrm{m}$ were observed, and the average grain size in this part was about $10 \mu \mathrm{m}$. In the lower part of the stirring zone there were grains from $3 \mu \mathrm{m}$ to $12 \mu \mathrm{m}$, with the average grain size being about $7 \mu \mathrm{m}$. Differences in the degree of microstructure refinement at various locations in $S Z$ are shown in Figure 4, while Figure 5 shows the microstructure at the border between BM and SZ with overlapping TMAZ and HAZ.

a)
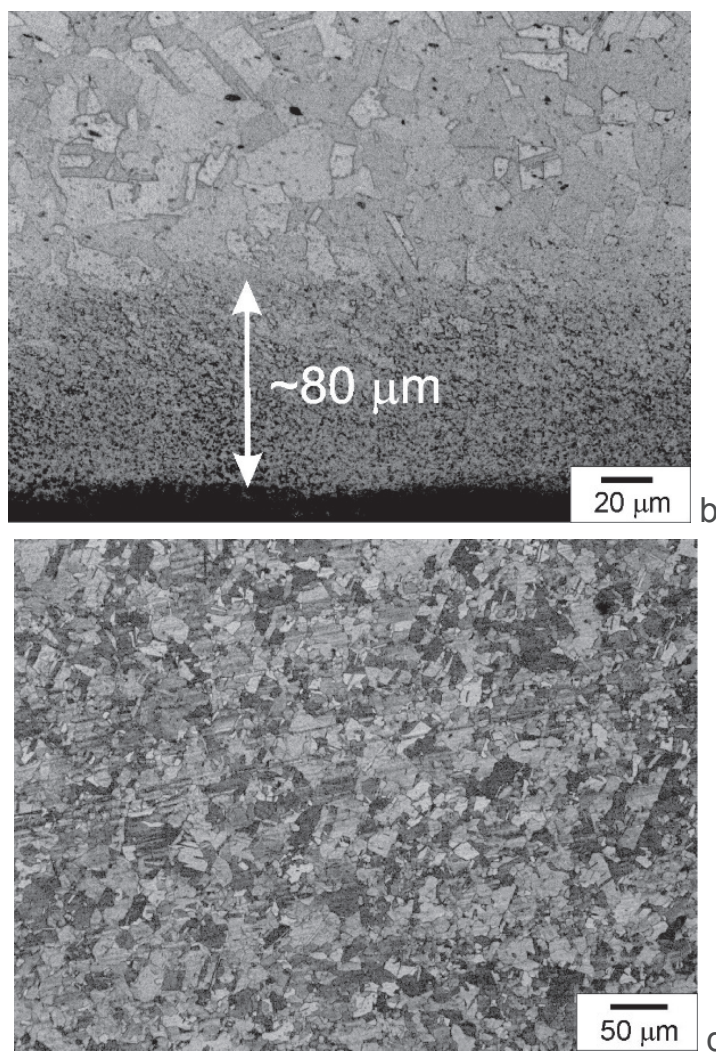
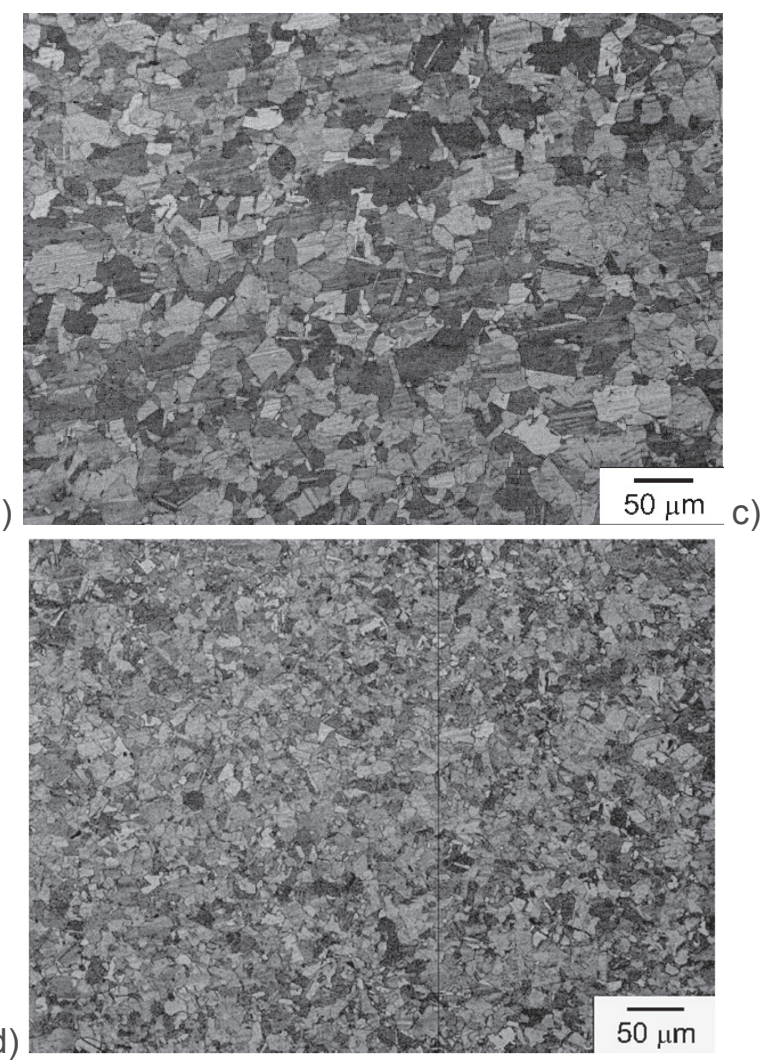

Figure 4 Copper microstructure after friction modification, a) narrow subsurface zone $(\sim 80 \mu \mathrm{m})$, b) upper part of stirring zone, following subsurface zone, c) central part of $S Z$, d) lower part of $S Z$. $N=1,000 \mathrm{rpm}$,

$$
\mathrm{V}=60 \mathrm{~mm} / \mathrm{min} \text {. Light microscopy, etched }
$$

The strong refinement of the material microstructure in the stirring zone is a consequence of the dynamic recrystallization of the material caused by the treatment. This process is a consequence of strong deformation of the material and an effect of the high temperature that accompanies the treatment. Differences in the degree of grain refinement in various SZ locations should be explained by differences in the time of heat influence on the material and in the temperature heights to which the material was heated up during processing. As is generally known, the main source of heat during FSP is primarily the friction of the shoulder against the surface of the material, while the friction arising during pin operation generates a much lower thermal effect. Hence, in the upper parts of the stirring zone the actual temperature to which the material was heated up was higher 
than in the lower part of this zone. In addition, in the case of the lower parts of the stirring zone, the heat dissipation rate increased as a result of contact of the sample surface with the massive machine tool matrix on which the sample lay. This reduced the temperature in the lower part of the stirring zone and translated into a higher degree of grain refinement. In turn, the higher temperature occurring in the upper parts of the SZ and the longer time of heat influence on the material favored grain growth in this place. Only in the case of the narrow subsurface zone, in which exceptionally strong grain refinement was observed, it should be assumed that this effect was caused by intensified mechanical deformation of the material, partially compensating for the effect of prolonged heat influence on the material. The grain size after recrystallization also depends on the degree material deformation. In contrast to the SZ, in the narrow

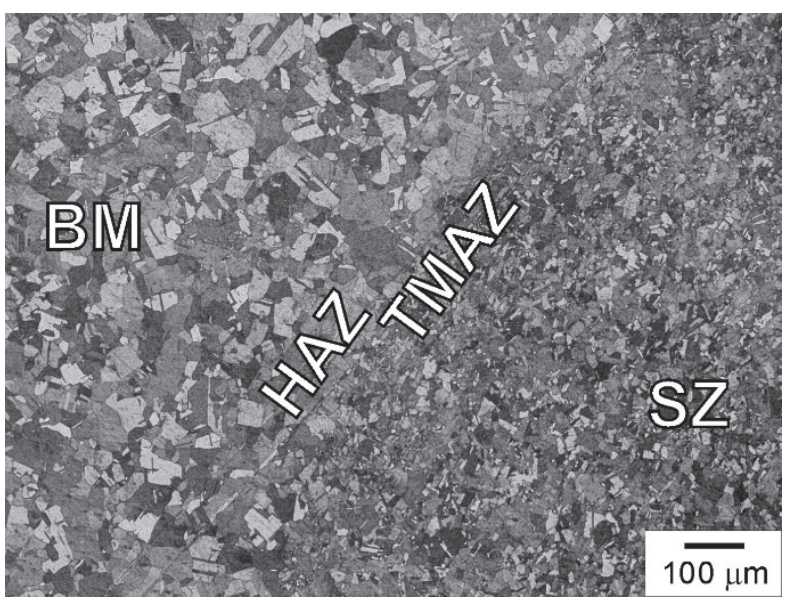

Figure 5 Boundary of microstructural changes. $\mathrm{N}=1,000 \mathrm{rpm}, \mathrm{V}=60 \mathrm{~mm} \cdot \mathrm{min}^{-1}$. Light microscopy, etched TMAZ zone, grains of an elongated shape dominated, the shape of which shows that dynamic recrystallization did not occur in this place. In turn, in the HAZ grains larger than those observed in the SZ but smaller than in the BM were present. The transition zone between the TMAZ and HAZ was characterized by a gradual increase in grain size.

\subsection{Hardness measurement}

The microstructural changes induced in the copper surface layer by FSP treatment contributed to a significant increase in the hardness of the material. The highest hardness of up to $103 \mathrm{HV} 0.1$ was recorded in the narrow subsurface zone characterized by the highest degree of grain refinement. The average hardness for this zone was $98 \mathrm{HV} 0.1$ and it was $54 \%$ higher than the hardness of the starting material, whose hardness was about $64 \mathrm{HV} 0.1$. In the case of the zone following the subsurface zone, the average hardness of copper in this zone was about $76 \mathrm{HV} 0.1$ and it was higher by almost $20 \%$ than that of the starting material. The average hardness in the central part of the stirring zone was about $82 \mathrm{HV} 0.1$, and in the lower part of the stirring zone it was about $91 \mathrm{HV} 0.1$; they were therefore higher by almost $30 \%$ and $43 \%$ respectively than the hardness of the starting material. The increase in hardness and the diversification of material hardness depending on the distance from the surface can be explained by differences in the degree of refinement of the material microstructure. The higher the degree of grain refinement, the higher the material hardness.

\section{CONCLUSIONS}

As a result of the simultaneous interaction of heat resulting from the friction and pressure of the tool on the material, there was dynamic recrystallization of the copper, the consequence of which was strong refinement of the microstructure in the stirring zone. Equiaxed grains with dimensions depending on the distance from the surface dominated in this zone. In the narrow subsurface zone, grains of less than $5 \mu \mathrm{m}$ in size were observed; in the area following the subsurface zone grains with an average size of $18 \mu \mathrm{m}$ dominated. In the central part the $S Z$ there were grains with an average size of about $10 \mu \mathrm{m}$, while in the lower part of the $S Z$ there were grains the average size of which was $7 \mu \mathrm{m}$. The obtained results prove that the differences in the degree of microstructure refinement at various locations in the SZ result from the differences in the magnitude of the thermal effect affecting the copper and the time of its impact on the material. The consequence of the changes in the copper microstructure, and especially the strong grain refinement, was a significant increase in the hardness of the material, which in the case of the subsurface zone exceeded the initial hardness by $50 \%$. The conducted research and obtained results indicate that FSP technology is a method that leads to beneficial 
microstructural changes, in particular strong grain refinement and an increase in the hardness of the material. This method can be an alternative solution to other methods used in the process of copper surface layer modification.

\section{REFERENCES}

[1] IWASZKO, J., KUDŁA, K., FILA, K. and STRZELECKA, M. The effect of friction stir processing (FSP) on the microstructure and properties of AM60 magnesium alloy. Archives of Metallurgy and Materials. 2016. vol. 61, no. 3, pp. 1209-1214.

[2] KOCAŃDA, D., HUTSAYLYUK, V., ŚLĘZAK, T., TORZEWSKI, J., NYKYFORCHYN, H. and KYRYLIV, V. Fatigue crack growth rates of S235 and S355 steels after friction stir processing. Materials Science Forum. 2012. vol. 726 , pp. 203-210.

[3] THOMAS, W.M., NICHOLAS, E.D., NEEDHAM, J.C., CHURCH, M.G., TEMPLESMITH, P. and DAWES, C.J. Friction stir butt welding, International Patent Application No. PCT/GB92/02203, GB Patent Application no. 9125978.8 (1991) and U.S. Patent no. 5460317 (1995).

[4] NANDAN, R., ROY, G.G., LIENERT, T.J. and DEBROY, T. Numerical modelling of 3D plastic flow and heat transfer during friction stir welding of stainless steel. Science and Technology of Welding and Joining. 2006. vol. 11 , no. 5, pp. 526-537.

[5] WOJSYK, K. and KUDŁA, K., Analysis of tool structure and development of tool geometry for joining metallic alloys using FSW methods. Przegląd Spawalnictwa. 2015. vol. 87, pp. $42-44$.

[6] MISHRA, R.S., ANSHUL, J., JEGENATHAN, V. and RANGANATH, M.S. Synthesis of copper -graphite composite using friction stir processing and evaluating parameters effecting hardness and wear. International Journal of Research in Engineering and Innovation. 2017. vol.1, no. 3, pp. 199-208.

[7] SATHISKUMAR, R., MURUGAN, N., DINAHARAN, I. and VIJAY, S.J. Role of friction stir processing parameters on microstructure and microhardness of boron carbide particulate reinforced copper surface composites. Sadhana. 2013. vol. 38, no. 6, pp. 1433-1450.

[8] IWASZKO, J., KUDŁA, K. and FILA, K. Technological aspects of friction stir processing of AIZn5.5MgCu aluminum alloy, Bulletin of the Polish Academy of Sciences. Technical Sciences, 2018. vol. 66, no. 5, pp. 713719.

[9] SANTELLA, M.L., ENGSTROM, T., STORJOHANN, D. and PAN, T.Y. Effects of friction stir processing on mechanical properties of the cast aluminum alloys A319 and A356. Scripta Materialia. 2005. vol. 53, pp. 201-206.

[10] CHEN, Y.C. and NAKATA, K. Evaluation of microstructure and mechanical properties in friction stir processed SKD61 tool steel. Materials Characterization. 2009. vol. 60, pp. 1471-1475.

[11] MORISADA, Y., FUJII, H., MIZUNO, T., ABE, G., NAGAOKA, T. and FUKUSAMI, M. Modification of thermally sprayed cemented carbide layer by friction stir processing. Surface \& Coatings Technology. 2010. vol. 204, pp. 2459-2464.

[12] SALAHI, S. and REZAZADEH, V. Fracture mechanism in friction stir processed annealed pure copper samples. World Applied Sciences Journal. 2013. vol. 23, no. 12, pp. 54-58.

[13] HODA, M.N., SINGARI, R.M. and ARULMONI, V.J. Friction stir processing (fsp) of copper and enhancement of its mechanical properties using graphite powder (C). International Journal of Research and Scientific Innovation. 2016. vol. III, no. IX, pp. 58-65.

[14] CARTIGUEYEN, S. and MAHADEVAN, K. Role of friction stir processing on copper and copper based particle reinforced composites - a review. Journal of Materials Science \& Surface Engineering. 2015. vol. 2, no. 2, pp 133145.

[15] CARTIGUEYEN, S., SUKESH, O.P. and MAHADEVAN, K. Numerical and experimental investigations of heat generation during friction stir processing of copper. Procedia Engineering. 2014. vol. 97, pp. 1069-1078. 